\title{
Non-random seasonal variation in the structure of a Mediterranean snake community
}

\author{
Ernesto Filippi and Luca Luiselli
}

Filippi, E. and Luiselli, L. 2007. Non-random seasonal variation in the structure of a Mediterranean snake community. - Web Ecol. 7: 40-46.

\begin{abstract}
The community structure in relation to habitat type was studied in a Mediterranean community of snakes from Canale Monterano, central Italy. Habitat data for snakes were analysed both overall and divided by season, i.e. spring (April-June) and summer (July-September). Community analyses were performed using null models (RA2 and RA3 algorithms) and Monte Carlo simulations on habitat niche overlap estimates. Null models suggested that the community was assembled non-randomly (according to RA2 but not RA3), indicating that the generalist-specialist nature (the number of resource states, but not necessarily the types) used by each species in the assemblage reduced ecological similarity. Similar results were reached also performing the same null model procedures on the spring datasets, whereas no structure emerged during summer either by RA 2 or RA 3 algorithms. In general, this study suggests that the community structure of snakes during spring may be shaped by the different eco-physiological needs of the various species (probably, the differential tolerance to cold and the consequent needs of finding suitable hibernacula), whereas the lack of structure during summer may be caused by the between-species similar foraging needs.
\end{abstract}

E. Filippi (ernesto.filippi@fastwebnet.it), FI.Z.V. Herpetology Section, via Gabrio Casati 43, I-00139 Roma, Italy, L. Luiselli, F.I.Z.V. Ecology Section, and Centre of Environmental Studies 'Demetra s.r.l.', via Olona 7, I-00198 Roma, Italy.

In community ecology studies, including the present case, 'structure' in a given assemblage of species is usually defined as the situation in which the various sympatric species partition the niche resource available in a mathematically predictable way, that can be investigated properly by null model analyses (Gotelli and Graves 1996). A null model is a pattern-generating model that is based on randomisation of ecological data or random sampling from a known or specified distribution (Gotelli and Graves 1996, Gotelli and McGill 2006). The null model is designed with respect to some ecological processes of interest for the experimenters, and is built in such a way that some elements are held constant and others are allowed to vary stochastically to create new assemblage patterns (the socalled 'pseudocommunities') with the randomisation be- ing designed to produce a pattern that would be expected in the absence of a particular ecological mechanism (Gotelli and McGill 2006). Therefore, null models work as standard statistical null hypotheses for detecting patterns (Gotelli and Ellison 2004). Because of the utility of null models in testing a broad variety of community ecology issues, this type of analysis is very useful if we are to understand whether a given community is randomly organized or is governed by structuring forces, e.g. by interspecific competition and/or resource partitioning patterns (Gotelli and Graves 1996, Sanderson et al. 1998, Gotelli 2000, Liu 2001, Lehsten and Harmand 2006).

Snakes were for a long time considered unsuitable for community ecology studies because of their elusive habits and low density (Toft 1985). However, they have now 
achieved the status of 'model animals' in several fields of evolutionary ecology research (Shine and Bonnet 2000), including community ecology (Luiselli 2006a). Indeed, the structure of snake communities worldwide was recently reviewed in order to identify general patterns of guild organization, assembly rules (Luiselli 2006a), abundance, and rarity in relation to a suite of geographic and ecological factors (Luiselli et al. 2005, Luiselli 2006b, 2006c). These studies not only clarified several broad community ecology patterns of snakes, but also provided the basis for further conceptual and empirical development. For instance, it is now clear that many snake communities worldwide are governed by interspecific competition (this 'rule' being mainly valid for tropical communities), with the trophic niche being usually the partitioned axis, and with broad geographic patterns for snake community assembly rules (Luiselli 2006a). Concerning the relatively species-rich snake communities of terrestrial habitats in Mediterranean Europe, it has been shown that various species often cooccur in close syntopy (Bruno and Maugeri 1990), and feed on different prey sizes, but still feed mostly on the same prey species (Luiselli 2006a).

Mediterranean environments are strongly seasonal (cold winter, cool and rainy spring, dry and hot summer), and variation in the snake community structure may occur in relation to seasonality. However, the seasonal variability in the Mediterranean snake community structure has not been examined up to now. Indeed, seasonality has been demonstrated to be a crucial determinant of structure patterns in snake communities from other regions with seasonal climatic conditions (Luiselli 2006a, 2006d).

In this paper we analyse the seasonal variations in the snake community structure at a Mediterranean area in central Italy, focusing our interest on the habitat type niche axis. This snake community has been intensely studied during the last 20 years (Luiselli and Rugiero 1990, Filippi and Luiselli 2006, Luiselli and Filippi 2006), and is therefore well suited for analysis of seasonal variations. We aim at answering the following key questions: (1) is the Mediterranean snake community under study randomly assembled in terms of habitat type? (2) Are there seasonal variations in community structure? (3) If so, can we predict which reasons shaped the seasonal differences in community structure?

\section{Materials and methods}

\section{Study area}

The field study was carried out at the 'Riserva Naturale Monterano', situated about $50 \mathrm{~km}$ north of Rome (Tolfa Mountains, Latium, central Italy). More details of the study area are given elsewhere (Filippi 1995, Filippi and Luiselli 2006, Luiselli and Filippi 2006). This hilly area
(150 to $250 \mathrm{~m}$ a.s.l. elevation) is characterized by a Mediterranean-temperate climate, with cold winters (usually without snow), rainy spring and autumn, and dry and hot summer. Snakes at the study area emerge from hibernation at the end of March, mate by April to mid June, have a long foraging season till the end of September, and enter into hibernation by the end of October (Filippi 1995).

\section{Protocol}

The field study was conducted at the various habitat types available in the study area for a total of 693 hours of field effort (334 h in Luiselli and Rugiero 1990, plus $359 \mathrm{~h}$ in Filippi and Luiselli 2006). In the various appropriate habitats (below), we searched for snakes by time-fixed routes. Each route in each habitat type was surveyed by two independently walking searchers, and was 60 min long. During a day with optimal weather (sunny and moderately warm), we typically carried out at least one-time fixed route in at least five different habitats, and the sequence of habitat types surveyed varied randomly in such a way to maintain a relatively constant field effort in each habitat type. Although it was impossible to exactly standardize the field effort in each habitat type, in relation to the relative availability of the habitat type in the landscape, every possible effort was done to minimize eventual biases among habitats. In addition, stones and tree branches were lifted to check for presence of snakes under cover objects, and aluminium sheets were randomly placed on the ground (maintaining the same density in each habitat type, that is: 10 sheets of $1 \times 1 \mathrm{~m}$ surface per each hectare of a given habitat type) to allow snakes to hide under them, and were inspected regularly. These procedures were used to mitigate potential data biases due to species-specific differences in elusiveness (MacKenzie et al. 2003, Wintle et al. 2004), given that nowadays there is evidence from numerous radiotelemetry studies and of surveys using artificial shelters that data on habitat utilization of snakes which rely solely on visual encounter may be substantially biased due to interspecific, habitat-related, seasonal and annual variation in detection probability, and, if several workers are involved, due to differing skills in detecting the target species (reviewed by Reinert 1993).

The following habitat types were considered: (1) mixed oak (Quercus cerris, Q. pubescens) woodland (WDS); (2) grassy pastures (GPS); (3) bushlands with Cytisus scoparius as the prominent taxon (CTS); (4) streams and their banks (STR); (5) ponds situated at the locality called 'Mercareccia' (PON); (6) dry-stone walls (SWL); (7) cultivations around the main town (CUL). Snakes were captured by hand, measured for snout-vent length (to the nearest $\mathrm{mm}$ ), weighed (to the nearest $\mathrm{g}$ on an electronic balance), and individually marked by ventral scale clipping for future identification. 


\section{Statistical and simulations analyses}

In this paper, we colleted data from surveys conducted during the late 1980s (Luiselli and Rugiero 1990) and in 2002-2003 (Filippi and Luiselli 2006, Luiselli and Filippi 2006). This was done because it was demonstrated in a previous article that there were only minor differences in the survey results (number of specimens divided by species and by habitat type) of the late 1980s and of 2002-2003 (Filippi and Luiselli 2006), i.e. all the snake species consistently exhibited species-specific habitat preferences that remained the same over the two survey periods. However, to avoid pseudo-replication of data (Hurlbert 1984), habitat type was recorded only once from each individual (i.e. it was not kept in recaptured individuals).

Data were analysed both overall and divided by season. For seasonal analyses, data were subdivided into two groups: spring, including data from April to June, and summer, from July to September. The similarity in habitat use among the various snake species was calculated by the overlap indices of Pianka (1973) and Czechanowski (Feinsinger et al. 1981), with values from 0 (no similarity) to 1 (absolute identity). As we did not have a static measure of habitat type availability at the study area, we therefore used the default setting of equiprobable resource states available in Ecosim software (Laurent and Kingsbury 2003).

To evaluate whether the study community was structured randomly or not, we contrasted the actual data matrix with random "pseudo-communities" generated by Monte Carlo simulations (Gotelli and Graves 1996). The original species utilization matrices were randomised by shuffling the original values among the resource states (randomisation algorithms RA2 and RA3 of Lawlor 1980). RA2 tests for structure in the generalist-specialist nature of the resource utilization matrix by conserving guild structure, but destroying observed niche breadth (Gotelli and Graves 1996). RA3 tests for guild structure by conserving niche breadth for each species, but destroying guild structure manifested by the zero structure of the resource utilization matrix (Gotelli and Graves 1996). For each pair of species, $3 \times 10^{4}$ random Monte Carlo permutations were generated. This number of permutations is enough to avoid algorithm biases in calculations (Lehsten and Harmand 2006). Niche overlap values were calculated for each of these randomly generated matrices, and species-pair and community-summary statistics were computed (Friggens and Brown 2005). Actual overlap values were then compared to the distributions of the expected values.

We used the Ecosim software (Aquired Intelligence Corp., Kesey-Bear; http://www.uvm.edu/biology/Faculty/ Gotelli/Gotelli.html) to calculate overlap indices and to generate Monte Carlo simulations. All other statistics were conducted using SPSS (SPSS 11.0 for Windows) and Statistica (Statistica 6.4 for Windows), with all tests being two-tailed and alpha set at 0.05 .

\section{Results}

\section{Overall analysis}

In total, we captured 525 snaks belonging to the five species studied here, and recaptured 179 individuals. The percentage of recaptured individuals ranged from $20.3 \%$ in the case of Hierophis viridiflavus to $68.8 \%$ in the case of Vipera aspis (full data in Filippi and Luiselli 2006). The percentage of snakes found under shelter ranged from approximately $8 \%$ (V. aspis and $H$. viridiflavus) to over $22 \%$ (Zamenis longissimus and Elaphe quatuorlineata). Overall, a General Linear Model (full factorial design) revealed no effect of species $\left(\mathrm{F}_{49}=4.197, \mathrm{p}=0.074\right)$ or season $\left(\mathrm{F}_{18}=\right.$ $1.853, \mathrm{p}=0.210$ ) on the proportion of snakes found under shelter.

The number of snakes observed in relation to habitat type is presented in Fig. 1.

Overlap indices of Pianka and Czechanowski showed high values especially between $V$. aspis and $Z$. longissimus, and between $H$. viridiflavus and E. quatuorlineata (Table 1). Monte Carlo simulations of the data matrix by RA2 algorithm revealed that the observed mean value $(0.453)$ was significantly less than the mean of simulated indices $(0.681 \pm 0.003)\left(\mathrm{p}_{\text {obs }<\exp }=0.00001 ; \mathrm{p}_{\text {obs }>\exp }=1.0\right)$, that indicates that the generalist-specialist nature (the number of resource states, but not necessarily the types) used by each species in the assemblage reduces ecological similarity. Monte Carlo simulations of the data matrix by RA3 algorithm revealed that the observed mean value $(0.453)$ was not significantly different from the mean of simulated indices $(0.438 \pm 0.005)$ ( $\left.p_{\text {obs }<\exp }=0.644 ; p_{\text {obs }>\exp }=0.356\right)$, that indicates that the qualitative guild structure (types of resources, but not necessarily the number of resource states) of the assemblage did not reduce ecological similarity.

\section{Seasonal analyses}

For the seasonal analyses, we deleted E. quatuorlineata due to its too small sample size. The number of snakes observed in relation to habitat type is presented in Fig. 2a (spring sample) and $2 \mathrm{~b}$ (summer sample).

\section{Spring}

Overlap indices of Pianka and Czechanowski indicated high similarity in habitat use especially between $V$. aspis and $Z$. longissimus, with $H$. viridiflavus and $N$. natrix being the species exhibiting the least similarity with each of the other species (Table 2). Monte Carlo simulations of the data matrix by RA2 algorithm revealed that the observed mean value (0.333) was significantly lesser than the mean of simulated indices $(0.534 \pm 0.004)\left(\mathrm{p}_{\mathrm{obs}<\exp }=0.00001\right.$; 


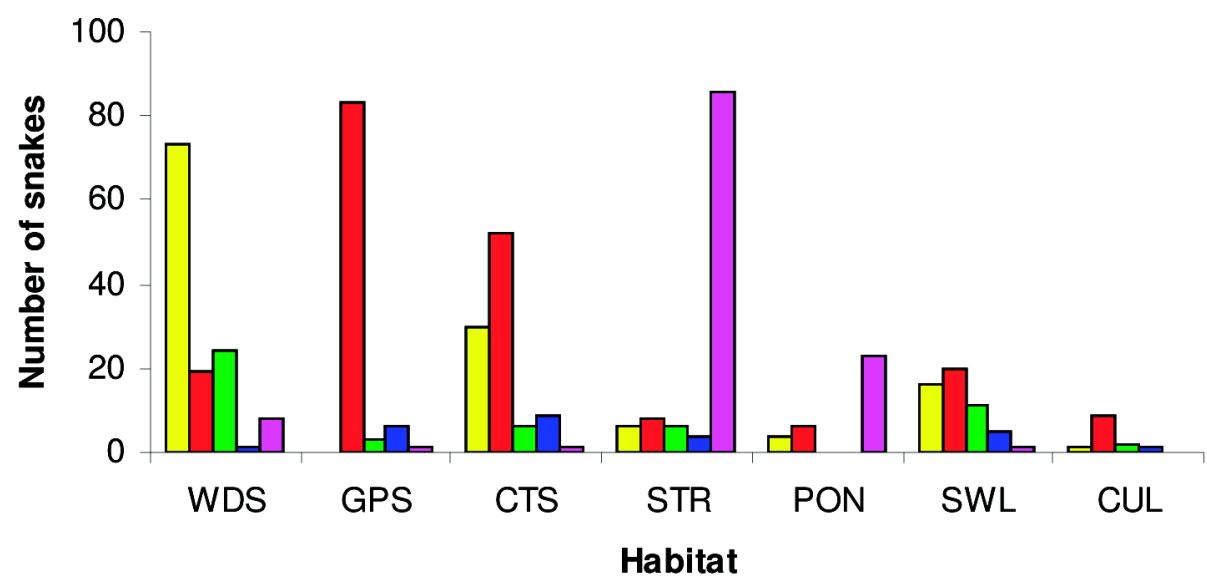

Fig. 1. Number of snakes observed at the study area in relation to the habitat of observation. Note that only the data relative to the five most common species were retained for this graph.

$\left.\mathrm{p}_{\text {obs }>\exp }=1.0\right)$, that indicates that the generalist-specialist nature (again, the number of resource states, but not necessarily the types) used by each species in the assemblage reduces ecological similarity. Monte Carlo simulations of the data matrix by RA3 algorithm revealed that the observed mean value (0.333) was not significantly different from the mean of simulated indices $(0.366 \pm 0.004)\left(\mathrm{p}_{\text {obs }<\exp }=\right.$ $\left.0.325 ; \mathrm{p}_{\mathrm{obs}>\exp }=0.675\right)$, that indicates that the qualitative guild structure (types of resources, but not necessarily the number of resource states) of the assemblage does not reduce ecological similarity.

\section{Summer}

Overlap indices of Pianka and Czechanowski indicated the same general patterns as in spring, i.e., a high similarity in habitat use especially between $V$. aspis and $Z$. longissimus. However, $H$. viridiflavus showed a much higher affinity with $V$. aspis than during spring, whereas $N$. natrix remained well distinct from all the other species (Table 3). Monte Carlo simulations of the data matrix by RA2 algorithm revealed that the observed mean value $(0.378)$ was marginally non-significantly lesser than the mean of simu- lated indices $(0.498 \pm 0.005)\left(\mathrm{p}_{\text {obs }<\exp }=0.052 ; \mathrm{p}_{\text {obs }>\exp }=\right.$ $0.948)$, that indicates that the generalist-specialist nature used by each species in the assemblage does not reduce ecological similarity. Monte Carlo simulations of the data matrix by RA3 algorithm revealed that the observed mean value $(0.378)$ was not significantly different from the mean of simulated indices $(0.285 \pm 0.005)\left(\mathrm{p}_{\text {obs }<\exp }=0.910 ; \mathrm{p}_{\text {obs }}\right.$ $>\exp =0.090)$, that indicates that the qualitative guild structure (types of resources, but not necessarily the number of resource states) of the assemblage does not reduce ecological similarity.

\section{Discussion}

\section{Is the Mediterranean snake community under study randomly assembled as for the habitat type resource is concerned?}

Overall, the present study revealed that the snake community of Monterano showed a non-random structure for habitat type resource. The fact that this non-random pat-

Table 1. Habitat use similarity for the various snake species assessed by calculating Pianka (above diagonal) and Czechanowski (below diagonal) overlap indices. Equiprobable resource use is assumed in this analysis.

\begin{tabular}{llllll}
\hline & V. aspis & H. viridiflavus & Z. longissimus & E. quatuorlineata & N. natrix \\
\hline V. aspis & $* * * *$ & 0.4034 & 0.9491 & 0.4380 & 0.1713 \\
H. viridiflavus & 0.5075 & 0.4501 & 0.4539 & 0.8673 & 0.1235 \\
Z. longissimus & 0.7538 & 0.7138 & 0.5577 & 0.5004 & 0.2912 \\
E. quatuorlineata & 0.4461 & 0.1627 & 0.2070 & $* * *$ & 0.3290 \\
N. natrix & 0.1602 & & & $* .2173$ & $* * *$ \\
\hline
\end{tabular}


(a)
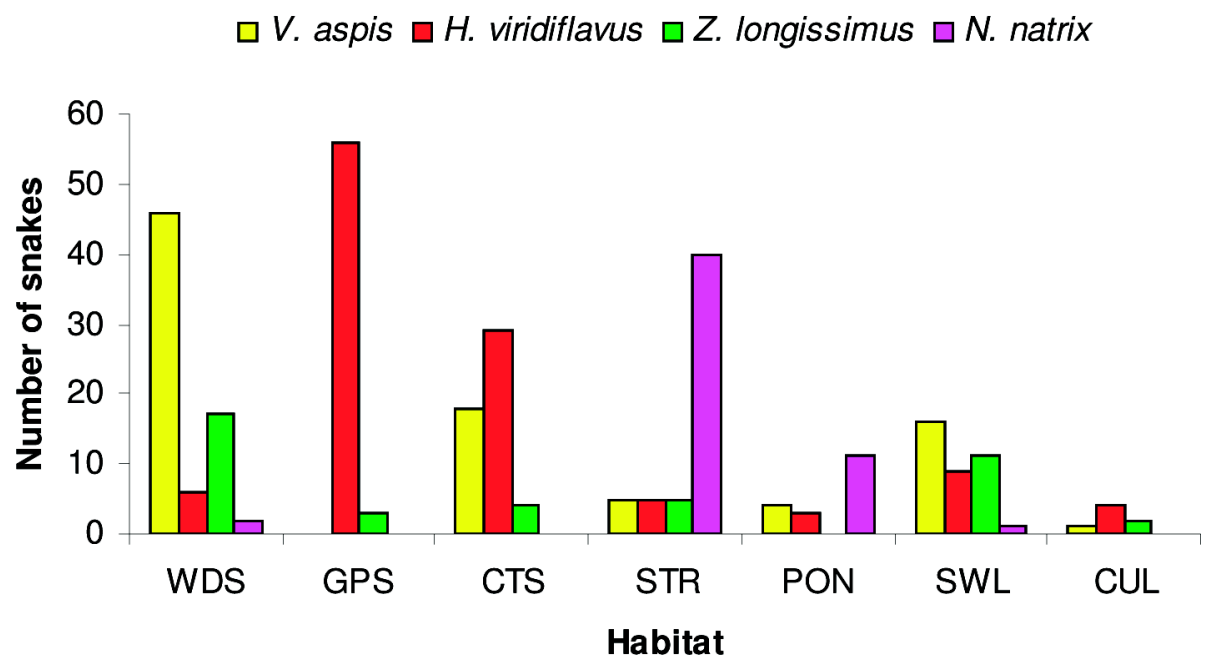

(b)

$\square$ V. aspis $\square$ H. viridiflavus $\square Z$. longissimus $\square N$. natrix

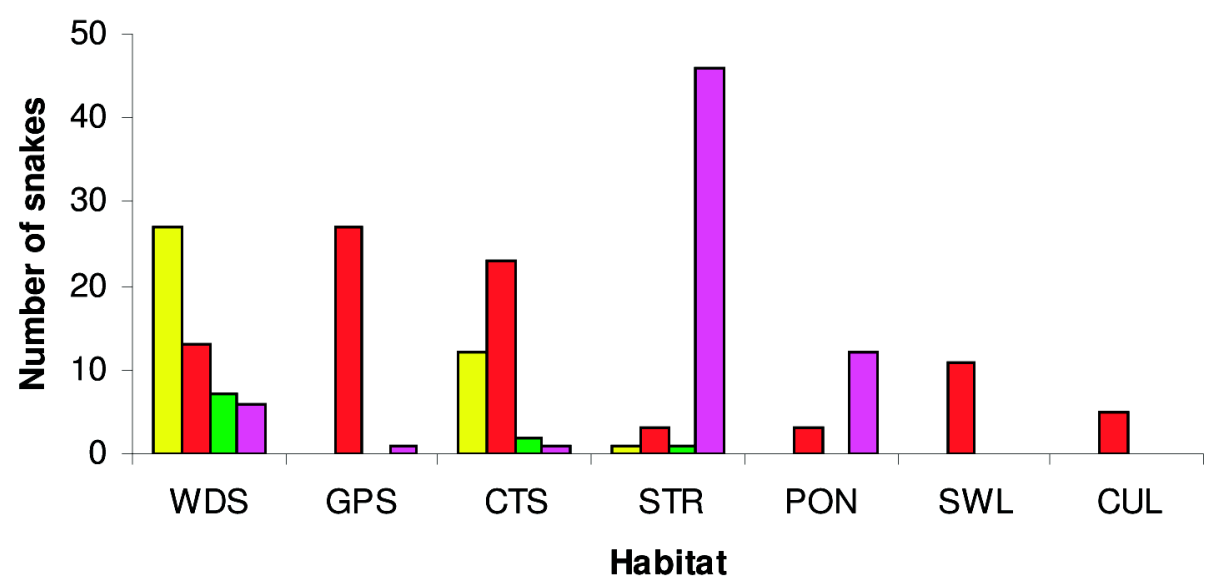

Fig. 2. Number of snakes observed at the study area in relation to the habitat of observation, during spring (a) and summer (b).

tern was evident by using RA2 but not RA3 algorithms suggests that the structure is due mainly to the different specialist-generalist nature of the various co-occurring species. In general, this is in agreement with Luiselli's (2006a) conclusion that most snake communities worldwide are not randomly assembled. However, the present study shows that in Mediterranean snake communities there is not only a non-random structure in the trophic niche axis (with non-random differences among species in prey size but not in prey type, Luiselli 2006a), but also in the habitat type axis.

\section{Are there seasonal variations in community structure?}

The annual cycle of every snake species in the Mediterranean environment is conditioned by the hibernation pe- 
Table 2. Habitat use similarity for the various snake species assessed by calculating Pianka (above diagonal) and Czechanowski (below diagonal) overlap indices during spring. Equiprobable resource use is assumed in this analysis.

\begin{tabular}{lllll}
\hline & V. aspis & H. viridiflavus & Z. longissimus & N. natrix \\
\hline V. aspis & $* * * *$ & 0.2918 & 0.9378 & 0.1619 \\
H. viridiflavus & 0.4165 & $* * * *$ & 0.3736 & 0.0949 \\
Z. longissimus & 0.7444 & 0.3809 & $* * * *$ & 0.2738 \\
N. natrix & 0.1556 & 0.1270 & 0.1746 & $* * * *$ \\
\hline
\end{tabular}

riod and by the summer foraging period (Bruno and Maugeri 1990). The hibernation period forces the snakes to find suitable sites for surviving the winter cold, and if these suitable sites are limited, there may be some competition between individuals to find good hibernacula (Luiselli 2006a). In addition, the hibernacula should be spatially arranged in such a way to allow snakes to mate easily within a few weeks after the beginning of the spring activity. On the other hand, the summer foraging areas should allow snakes to find their appropriate prey easily, and they often are quite distant from the hibernacula and snakes may spend considerable time to reach foraging areas (Bruno and Maugeri 1990). Concerning our study area, the same main patterns also apply. For instance, radiotracked snakes at our study area employed an average of $3.4 \pm 6.2$ days ( $\mathrm{n}=36$ individuals monitored) to leave their winter shelter to reach a foraging site, and their foraging areas were $85-1440 \mathrm{~m}$ distant from the hibernacula (with great interindividual and interspecific differences).

Based on the above-mentioned evidence, we may predict that snake community structure may be different between spring and summer. More in detail, non-random structure in habitat type may be predicted if the various species exhibit different eco-physiological tolerance to cold winters, i.e., if the various species should select different hibernacula on the basis of their value as refuges to prevent death from the winter climate. This is probably true because the snake community under study includes species clearly well resistant to cold climates (and therefore found also in high altitude places in central Italy, like V. aspis and N. natrix; Bruno and Maugeri 1990) and others which are found only in hot low-altitude Mediterranean bushlands (like Elaphe quatuorlineata; Bruno and Maugeri 1990). On the other hand, foraging habitat should not matter given that Mediterranean snakes do not eat during winter and also very rarely do so during the early spring (Bruno and Maugeri 1990).

Non-random structure in habitat type during summer may be predicted if the species are characterized by different prey type preferences, given that foraging and prey searching are the main activities of Mediterranean snakes during summertime. However, previous studies demonstrated that co-occurring Mediterranean snakes tend to feed on the same prey type, although partitioning the prey size (Luiselli 2006a). Therefore, there should not be an expected structure in the dataset collected during summer.

Our study suggests that, during spring there was a structure in the snake community mainly due to the specialist-generalist nature of habitat use by the various species (as revealed by RA2 simulations), whereas during summer this structure was less evident and not even statistically detectable. Thus, we are led to think that the different ecophysiological needs (probably, the different tolerance to cold by the various species and the consequent needs of finding suitable hibernacula) may be responsible of the spring community structure, whereas the between-species similar foraging needs may explain the lack of structure during summer time. This is in part confirmed by the fact that the more cold-resistant species (V. aspis and $N$. natrix) were often seen in communal hibernacula that were avoided by the other species, being situated in densely vegetated, relatively cool spots inside the study area (Filippi and Luiselli, unpubl.). The same did not apply to $Z$. longissimus and, especially, E. quatuorlineata that selected hibernacula in hot, well exposed rocky or stony places with scarce vegetation.

In general, we hypothesize that these findings may be generalised to many other Mediterranean snake communities from elsewhere. This is because the main ecological factors that seem to have shaped the community structure

Table 3. Habitat use similarity for the various snake species assessed by calculating Pianka (above diagonal) and Czechanowski (below diagonal) overlap indices during summer. Equiprobable resource use is assumed in this analysis.

\begin{tabular}{lllll}
\hline & V. aspis & H. viridiflavus & Z. longissimus & N. natrix \\
\hline V. aspis & $* * * *$ & 0.5342 & 0.9850 & 0.1552 \\
H. viridiflavus & 0.4485 & $* * * *$ & 0.4776 & 0.1579 \\
Z. longissimus & 0.9000 & 0.3882 & $* * * *$ & 0.2555 \\
N. natrix & 0.1311 & 0.1918 & 0.2061 & $* * * *$ \\
\hline
\end{tabular}


in our study case (i.e. the need of finding suitable speciesspecific hibernacula, and the need of finding between-species similar foraging areas during summer) are likely widespread among Mediterranean snake communities.

Acknowledgements. - We would like to thank F.M. Angelici, U. Agrimi, and the anonymous referees for the valuable criticisms on an early version of this paper. LL and EF were supported by funds from the 'Parco Naturale Regionale di Canale Monterano'. Snakes were captured under authorization of the 'Regione Lazio - Assessorato Ambiente e Protezione Civile", and of the 'Natural Reserve of Canale Monterano' (authorization to EF and LL made by F.M. Mantero). No animals have been damaged or killed during the present project, and all were handled according to the standards of the Italian Ministry for Scientific Research and Technology.

\section{References}

Bruno, S. and Maugeri, S. 1990. Serpenti d'Italia e d'Europa. Editoriale Giorgio Mondatori, Milano, Italy.

Feinsinger, P., Spears, E. E. and Poole, R. W. 1981. A simple measure of niche overlap. - Ecology 62:27-32.

Filippi, E. 1995. Aspetti dell' ecologia di due comunità di Colubridi e Viperidi (Reptilia, Serpentes) di un' area dell' Italia centrale (Monti della Tolfa, Lazio). - Unpubl. Ph D. thesis, Univ. of Rome, Italy.

Filippi, E. and Luiselli, L. 2006. Changes in community composition, habitats and abundance of snakes after $10+$ years in a protected area in Italy: conservation implications. - Herpetol. J. 16:29-36.

Friggens, M. H. and Brown, J. H. 2005. Niche partitioning in the cestode communities of two elasmobranches. - Oikos 108:76-84.

Gotelli, N. J. 2000. Null model analysis of species co-occurrence patterns. - Ecology 81:2606-2621.

Gotelli, N. J. and Ellison, A. M. 2004. A primer of ecological statistics. - Sinauer.

Gotelli, N. J. and Graves, G. R. 1996. Null models in ecology.Smithsonian Inst. Press.

Gotelli, N. J. and McGill, B. J. 2006. Null versus neutral models: what's the difference? -Ecography 29:793-800.

Hurlbert, S. H. 1984. Pseudoreplication and the design of ecological field experiments. - Ecol. Monogr. 54:187-211.

Laurent, E. J. and Kingsbury, B. A. 2003. Habitat separation among three species of water snakes in Northwestern Kentucky. - J. Herpetol. 37:229-235.
Lawlor, L. R. 1980. Structure and stability in natural and randomly constructed competitive communities. - Am. Nat. 116:394-408.

Lehsten, V. and Harmand, P. 2006. Null models for species cooccurrence patterns: assessing bias and minimum iteration number for the sequential swap. - Ecography 29:786-792.

Liu, J. S. 2001. Monte Carlo strategies in scientific computing. Springer Verlag.

Luiselli, L. 2006a. Resource partitioning and interspecific competition in snakes: the search for general geographical and guild patterns. - Oikos 114:193-211.

Luiselli, L. 2006b. Testing hypotheses on the ecological patterns of rarity using a novel model of study: snake communities worldwide. - Web Ecol. 6:44-58.

Luiselli, L. 2006c. Broad geographic, taxonomic and ecological patterns of interpopulation variation in the dietary habits of snakes. - Web Ecol. 6:2-16.

Luiselli, L. 2006d. Interspecific relationships between two species of sympatric afrotropical water snake in relation to a seasonally fluctuating food resource. - J. Trop. Ecol. 22:91-100.

Luiselli, L. and Filippi, E. 2006. Null models, co-occurrence patterns, and ecological modelling of a Mediterranean community of snakes. - Amphib.-Reptil. 27:325-337.

Luiselli, L. and Rugiero, L. 1990. On habitat selection and phenology in six species of snakes in Canale Monterano (Tolfa Mountains, Latium, Italy) including data on reproduction and feeding in Vipera aspis francisciredi (Squamata: Viperidae). - Herpetozoa 2:107-115.

Luiselli, L., Akani, G.C., Rugiero, L. et al. 2005. Relationships between body size, population abundance and niche characteristics in the communities of snakes from three habitats in southern Nigeria. - J. Zool. Lond. 265:207-213.

MacKenzie, D. I. et al. 2003. Estimating site occupancy, colonization, and local extinction when a species is detected imperfectly. - Ecology 84:2200-2207.

Pianka, E. R. 1973. The structure of lizard communities. Annu. Rev. Ecol. Syst. 4:53-74.

Reinert, H. K. 1993. Habitat selection in snakes. - In Seigel R. A. and Collins, J. T. (eds), Snakes - ecology and behaviour, McGraw-Hill, pp. 201-240.

Sanderson, J. G. et al. 1998. Null matrices and the analysis of species co-occurrences. -Oecologia 116:275-283.

Shine, R. and Bonnet, X. 2000. Snakes: a new 'model organism' in ecological research? - Trends Ecol. Evol. 15:221-222.

Toft, C. A. 1985. Resource partitioning in amphibians and reptiles. - Copeia 1985:1-21.

Wintle, B. A. et al. 2004. Precision and bias of methods for estimating point survey detection probabilities. - Ecol. Appl. 14:703-712. 